\title{
Urgent Psychiatric Consultations at Mental Health Center during COVID-19 Pandemic: Retrospective Observational Study
}

\author{
Rosaria Di Lorenzo' ${ }^{1}$ - Gianluca Fiore ${ }^{2} \cdot$ Alessandra Bruno $^{3} \cdot$ Margherita Pinelli $^{2}$. \\ Davide Bertani ${ }^{2} \cdot$ Patrizia Falcone ${ }^{1} \cdot$ Donatella Marrama $^{4} \cdot$ Fabrizio Starace $^{5}$. \\ Paola Ferri ${ }^{6}$ (D)
}

Accepted: 28 February 2021 / Published online: 26 March 2021

(c) The Author(s), under exclusive licence to Springer Science+Business Media, LLC, part of Springer Nature 2021

\begin{abstract}
The coronavirus pandemic and related social distancing measures have brought about dramatic changes in people's lives. In particular, health workers have been forced to change their activities both for the different needs of patients and for preventive measures against the spread of the virus. This study is aimed at comparing the urgent psychiatric consultations (UPC) performed at the outpatient Mental Health Center (MHC) of Modena during the coronavirus outbreak period, from 1 March to 31 August 2020, with the same period in 2019. We retrospectively collected in a database the demographic and clinical characteristics of patients who required UPC in the MHC during the 6-month observation periods in both 2019 and 2020. Data were statistically analyzed. We analyzed 656 urgent psychiatric consultations in 2019 and 811 in 2020, requested by 425 patients in 2019 and 488 in 2020, respectively. In the pandemic period, we observed an increase in the total and daily number of UPC which were more frequently required by patients in care at local outpatient services in comparison with the previous period. During 2020, an increased number of UPC was carried out remotely and the outcome was more frequently represented by discharge at home, avoiding hospitalization as much as possible. In the course of the coronavirus pandemic, MHC had to face an increased demand for clinical activity especially from the most clinically and socially vulnerable patients, who more frequently required UPC in outpatient psychiatric services.
\end{abstract}

Keywords Coronavirus pandemic · COVID-19 - Mental Health Center · Urgent psychiatric consultations

Rosaria Di Lorenzo

saradilorenzo1@alice.it; r.dilorenzo@ausl.mo.it

Extended author information available on the last page of the article 


\section{Introduction}

In Italy, from March 2020 to the present, the biological risk of a pandemic coronavirus infection has involved the entire population. Coronaviruses are a large family of viruses known to cause illnesses ranging from the common cold to more serious diseases. The new Coronavirus, SARS-CoV-2, is a new strain of coronavirus that is responsible for the respiratory disease now called COVID-19 [1].

The numerous infections have led to a rapid pandemic spread of the virus which, as pointed out by some authors, represents the most disruptive public health event of all time [2], with massive impact on domains such as the health, social, economic and political fields. Therefore, many measures have been adopted to prevent and/or contain the infection in the population. The rapidity of the contagion, the severity of the infection, and the lack of vaccines or specific treatments have led many governments to institute drastic measures of quarantine and social confinement, going so far as to dramatically alter daily life activities [3].

As recently pointed out by WHO [4], the COVID-19 pandemic also represents a risk factor for the development, exacerbation and relapse of many psychiatric and substance use disorders $[5,6]$. Patients with a psychiatric condition may be more vulnerable to both the effects of infection and its consequences as well as to drastic social changes, leading to social isolation and/or exacerbating a pre-existing social withdrawal [7-10]. With the global development of the coronavirus disease (COVID-19) pandemic, the psychological problems accompanying this pandemic have rapidly increased the public health burden $[11,12]$.

The condition of social distancing, required to limit the spread of the virus, may increase the risk of clinical relapses and new episodes of illness. At the same time, if the pandemic were to continue for a long time, it could increase the risk of developing mental disorders, such as anxiety, mood, addiction, and thought disorders [13, 14]. In addition, objective social isolation and subjective feelings of loneliness can be associated with a higher risk of suicide [15]. The measures taken have a significant psychological impact on the population affected. Prolonged quarantine, fear of infection, frustration, boredom, and inadequate information represent potential stressors [16].

The COVID-19 pandemic represents a public health emergency of international concern, affecting not only physical health, but also mental health. Studies conducted on the SARS epidemic demonstrated that psychological effects can lead to severe and permanent mental problems [17]. Against this backdrop, priorities are also changing for the population, for psychiatrists and for other health professionals [18].

The American Psychiatric Association [19] defines psychiatric emergency as "an acute disturbance in thought, behavior, mood, or social relationship, which requires immediate intervention as defined by the patient, family, or social unit."

A psychiatric emergency requires immediate intervention to save the patient or others from imminent danger [20]. According to this definition, affected individuals typically have a diagnosis of manic episode, acute psychosis, suicidal or homicidal ideation. The causes of such severe behavioral disorders may vary and may be exacerbated by substance use, organic diseases, mood disorders, extreme anxiety or trauma [21].

Psychiatric emergencies are common in both inpatient and outpatient settings. They are estimated to account for between 6 and 25\% of emergency department consultations, whereas in the primary care setting, $10 \%$ of consultations are performed for psychiatric emergencies [20]. 
The three main reasons for urgent psychiatric consultation are [20]:

1. Acute psychosis and manic episode;

2. Depression with suicidal ideation;

3. Violent behaviour with heterodirected aggressive acts.

Giberti and Rossi [22] identify the most common psychiatric emergencies that represent a reason for consultation in the emergency department (ED) or in Mental Health Centers (MHCs): acute anxiety state; excited state; acute confusion state; acute psychosis; psychomotor arrest; depressive reaction; suicide attempt; self-harm.

Over the past few years, there has been a significant increase in consultation requests for psychiatric emergencies, particularly in large cities. Hospital emergency services are often overloaded with requests, which only in part appear related to psychopathological disorders that are strictly psychiatric. About 5-30\% of medical pathologies are associated with psychiatric symptoms, while true psychiatric emergencies are about $30-40 \%$ of those in which the intervention of the psychiatrist is required $[21,23]$.

In Italy, Departments of Mental Health and Drug Abuse (DSM-DA) are concerned with the promotion of mental health, the prevention, diagnosis and treatment of mental disorders and the rehabilitation of psychiatric patients [24]. In particular, DSM-DA carries out activities aimed at ensuring information, participation and active involvement of patients and their families [25]. In the area of Adult Mental Health, the integration between in- and outpatients is addressed in accordance with the criteria of intensity and continuity of care as well as the integration of primary care with social services, volunteers and associations in order to provide rehabilitative treatments. MHC is the place where community psychiatry is carried out since in MHC regular contact with patients is guaranteed and integration among many professionals is favored in order to implement personalized therapeutic-rehabilitative programs [26].

During the COVID-19 emergency, a remodeling of psychiatric services occurred all over the world [27-30]. Specifically, the DSM-DA in Modena has recently implemented new guidelines ("Operational indications for the activities of departments of mental health during coronavirus emergencies") issued by the Italian Society of Psychiatric Epidemiology [31].

Outpatient activities scheduled by MHCs have been reassessed through telephone contact in order to verify patients' health conditions [32]. During the course of each telephone interview, the professional provides information on the activities carried out by the MHC during pandemic social confinement and gives the patient an opportunity to maintain or reschedule their follow-up visit. Direct, urgent and unscheduled access has been guaranteed in case of necessity during normal opening hours of the service. Semi-residential activities, such as day centers and day hospitals, have been suspended. The changes in clinical activities required by the pandemic social distancing have caused a number of issues for patients treated at MHCs: group activities (group psychotherapy, psychoeducation groups, etc.) have been banned, follow-up consultations have been reduced as well as monitoring of psychopharmacological therapies [33]. 
The aim of the present study was to investigate the qualitative and quantitative changes which occurred in the urgent psychiatric consultations (UPC) performed at a MHC during the epidemic spread of COVID-19.

\section{Materials and Methods}

\section{Design and Period of the Study}

This is a retrospective observational study, which collected demographic and clinical data on patients who required UPC at the MHC of the DSM-DP of AUSL-Modena, during an observation period of 6 months (from $1^{\text {st }}$ March to 31 August) in 2019 and 2020, in order to investigate the qualitative and quantitative modifications in the period of social emergency due to COVID-19 pandemic during 2020 in comparison with the corresponding period of 2019 .

\section{Setting of the Study}

MHC in Modena is divided into two locations which cater for a population of 180.000 citizens and is aimed at providing regular and urgent consultations by its staff, composed of psychiatrists, psychologists, rehabilitative professionals and nurses. MHC is closely integrated with inpatients psychiatric services as well as community facilities and agencies in order to promote multi-professional programs aimed at patients' adjustment in their living environment.

\section{The Selected Variables}

We collected the following information regarding UPC:

- referral to UPC,

- setting of UPC,

- clinical motivations for UPC,

- therapeutic prescriptions and/or administration in UPC,

- UPC outcomes.

We collected the following demographic and clinical variables of patients who required UPC during the observation periods in 2019 and 2020:

- age, gender, nationality,

- housing context,

- work status,

- marital status,

- categorical psychiatric diagnosis (ICD-9-CM) [34],

- dual diagnosis (use of substances/alcohol in comorbidity),

- medical comorbidity,

- previous treatment and care in outpatient services. 


\section{Data Collection}

The data were collected from the informative database (InfoClin) of MHC. The collected data were anonymized by attributing to each selected patient a progressive alphanumeric code. The data were processed using statistical methods to obtain the information that constitutes the purpose of the research.

\section{Statistical Analysis}

Descriptive statistical analysis of the variables in our sample was carried out: mean and standard deviation, $t$-test for analysis of continuous variables; percentages and chi 2 tests for categorical variables; multiple logistic regression, stepwise backward model, between the dependent variable "UPC" (UPC in 2020 =1, UPC in 2019=0) and the other selected variables. The level of statistical significance was set at $p<0.05$. Data were analyzed through STATA12-2011.

\section{Ethical Considerations}

This research was conducted following the principles of the Declaration of Helsinki and according to good clinical practice behavior. The study manager and her collaborators have had access to the data, and are bound by the obligation of confidentiality and data processing according to current regulations. The data was stored anonymously and identified on the basis of the assigned alphanumeric code.

\section{Results}

\section{Urgent Psychiatric Consultations (UPC) at the MHC in the Observation Periods of 2019 and 2020}

We collected 656 urgent psychiatric consultations in 2019 and 811 in 2020, requested by 425 patients in 2019 and 488 in 2020, respectively. As shown in Table 1, the number of consultations per day is significantly higher in 2020 than in 2019, whereas there is not any statistically significant difference in the number of UPC per month or in the number of UPC per patient (Table 1).

In the observation periods of the two years (Table 1), the setting of UPC is statistically significantly different (Pearson chi2 $=55.48 ; p=0.000$ ); in particular, in 2020, the UPC carried out by means of telephone contact significantly increased compared to 2019. As shown in Table 1, who sent patients to UPC is statistically significantly different in the two years: in 2020, we reported an increase of spontaneous access to consultation and a reduction of patients referral to UPC from outpatient services in comparison with 2019 (Pearson chi $2=6.37 ; p=0.041)$. In 2020, more UPC were required by patients already in care with outpatient services in comparison with 2019 (Table 1).

We grouped the motivations for UPC on the basis of both the literature [20, 22] and the frequency observed. The motivations for UPC, shown in Table 2, do not statistically 
Table 1 Urgent Psychiatric Consultations (UPC) at MHC during the 6-month observation periods in 2019 and 2020

\begin{tabular}{|c|c|c|c|}
\hline Variables & $\begin{array}{l}\text { UPC from } 1 \text { March } \\
\text { to } 31 \text { August } 2019 \\
(n=656)\end{array}$ & $\begin{array}{l}\text { UPC from } 1 \text { March } \\
\text { to } 31 \text { August } 2020 \\
(n=811)\end{array}$ & Statistical test probability \\
\hline \multicolumn{4}{|l|}{ UPC per month, $n(\%)$} \\
\hline March & $103(16 \%)$ & $146(18 \%)$ & \multirow{6}{*}{$\begin{array}{l}\text { Pearson chi } 2=2.78 \\
p=0.734\end{array}$} \\
\hline April & $129(20 \%)$ & $153(19 \%)$ & \\
\hline May & $116(18 \%)$ & $141(17 \%)$ & \\
\hline June & $101(15 \%)$ & $125(15 \%)$ & \\
\hline July & $110(17 \%)$ & $144(18 \%)$ & \\
\hline August & $97(15 \%)$ & $102(13 \%)$ & \\
\hline \multicolumn{4}{|l|}{ UPC per day, $\mathrm{m} \pm \mathrm{SD}$} \\
\hline Number & $4.07 \pm 2.11$ & $5.3 \pm 2.64$ & $\begin{array}{l}t=-4.55, \text { t-test } \\
p=0.000\end{array}$ \\
\hline \multicolumn{4}{|l|}{ UPC per patient, $\mathrm{m} \pm \mathrm{SD}$} \\
\hline Number & $1.61 \pm 1.22$ & $1.66 \pm 1.41$ & $\begin{array}{l}t=-0.59, t \text {-test } \\
p=0.5531\end{array}$ \\
\hline \multicolumn{4}{|l|}{ UPC Setting, $n(\%)$} \\
\hline $\mathrm{MHC}$ & $559(85 \%)$ & $593(73 \%)$ & \multirow{4}{*}{$\begin{array}{l}\text { Pearson chi } 2=55.48 \\
\boldsymbol{p}=\mathbf{0 . 0 0 0}\end{array}$} \\
\hline Home visit & $48(7 \%)$ & $63(8 \%)$ & \\
\hline Telephonic consultation & $25(4 \%)$ & $126(16 \%)$ & \\
\hline $\begin{array}{l}\text { Others (hospital wards, } \\
\text { etc.) }\end{array}$ & $24(4 \%)$ & $29(4 \%)$ & \\
\hline \multicolumn{4}{|l|}{ Referral to UPC, $n(\%)$} \\
\hline $\begin{array}{l}\text { Spontaneous/General } \\
\text { practitioner }\end{array}$ & $583(89 \%)$ & $754(93 \%)$ & \multirow[t]{3}{*}{$\begin{array}{l}\text { Pearson chi } 2=6.37 \\
\boldsymbol{p}=\mathbf{0 . 0 4 1}\end{array}$} \\
\hline $\begin{array}{l}\text { MHC and/or outpatient } \\
\text { services }\end{array}$ & $53(8 \%)$ & $41(5 \%)$ & \\
\hline $\begin{array}{l}\text { Other medical special- } \\
\text { ists }\end{array}$ & $20(3 \%)$ & $16(2 \%)$ & \\
\hline \multicolumn{4}{|c|}{ Previous treatment and care of patients who required UPC, $n(\%)$} \\
\hline $\begin{array}{l}\text { UPC for patients already } \\
\text { treated in MHC or } \\
\text { in other outpatient } \\
\text { services }\end{array}$ & $518(79 \%)$ & $700(86 \%)$ & \multirow[t]{2}{*}{$\begin{array}{l}\text { Pearson chi } 2=13.90 \\
\boldsymbol{p}=\mathbf{0 . 0 0 0}\end{array}$} \\
\hline $\begin{array}{l}\text { UPC for patients not } \\
\text { previously treated in } \\
\text { MHC or other outpa- } \\
\text { tient services }\end{array}$ & $138(21 \%)$ & $111(14 \%)$ & \\
\hline
\end{tabular}

significantly differ between the two years (Table 2), although in 2020 we reported an increase in depressive symptoms $(26 \%)$, aggressiveness $(8 \%)$, social maladjustment $(7 \%)$ and insomnia (3\%).

On the contrary, we found a statistically significant difference between the two observation periods in the outcome of UPC, as shown in Table 3 (Pearson chi $2=15.45 ; p=0.017$ ), with an increase in discharging patients at home and a reduction in patients referral to the $\mathrm{MCH}$ in 2020 compared to the previous year. Another significant difference is represented 
Table 2 Clinical motivations for UPC during the 6-month observation periods in 2019 and 2020

\begin{tabular}{llll}
\hline $\begin{array}{l}\text { Clinical motivations for } \\
\text { UPC, } n(\%)\end{array}$ & $\begin{array}{l}\text { UPC from 1 March } \\
\text { to 31 August 2019 } \\
(n=656)\end{array}$ & $\begin{array}{l}\text { UPC from 1 March } \\
\text { to 31 August 2020 } \\
(n=811)\end{array}$ & Statistical test probability \\
\hline Depressive symptoms & $163(25 \%)$ & $214(26 \%)$ & Pearson chi2=14.54 \\
Anxiety symptoms & $150(23 \%)$ & $157(19 \%)$ & $p=0.204$ \\
Acute psychosis & $123(19 \%)$ & $130(16 \%)$ & \\
Aggressiveness & $46(7 \%)$ & $66(8 \%)$ & \\
Social maladjustment & $32(5 \%)$ & $54(7 \%)$ & \\
Suicidal behaviour & $18(3 \%)$ & $24(3 \%)$ & \\
Therapy adverse effects & $23(4 \%)$ & $21(3 \%)$ & \\
Insomnia & $11(2 \%)$ & $28(3 \%)$ & \\
Psychorganic symptoms & $10(2 \%)$ & $11(1 \%)$ & \\
Drug intoxication & $16(2 \%)$ & $13(2 \%)$ & \\
Manic state & $12(2 \%)$ & $74(2 \%)$ & \\
Others & $52(8 \%)$ & & \\
\hline
\end{tabular}

by the therapeutic prescription, which was statistically significantly less frequent in 2020 compared to the same period of 2019, as shown in Table 3 (Pearson chi $2=41.16$; $p=0.000)$.

\section{Individuals Who Required UPC at the MHC in the 6-Month Observation Periods of 2019 and 2020}

As shown in Table 4, the demographic characteristics of individuals who required UPC at the MHC in the observation periods of 2019 and 2020 are not statistically significantly different between the two years. In particular, there is the prevalence of females and Italian nationality in both years. The majority of patients in both years are single and live in acquired or parental family. Regarding work status, in $2019,31 \%$ of patients were unemployed, with a slight increase in 2020 (32\%).

Regarding the clinical characteristics of our patients (Table 5), the categorical psychiatric diagnosis (ICD-9-CM) [34], the use of substances / alcohol in comorbidity and the medical comorbidities, are not significantly different among the patients visited in UPC in the two years. We did not report any statistically significant difference between the two years regarding the patients who required one UPC in the observation period compared with those who required more than one UPC (Table 5).

\section{The Multiple Logistic Regression Between UPC and Selected Variables}

The selected variables statistically significantly related to UPC (dependent variable) carried out in the two years (UPC in $2020=1 ; 2019=0$ ) at multiple logistic regression, stepwise backward model, are represented by many psychiatric diagnoses or suspected mental conditions as well as the telephonic consultation, which are predictive of UPC in 2020 (Table 6). 


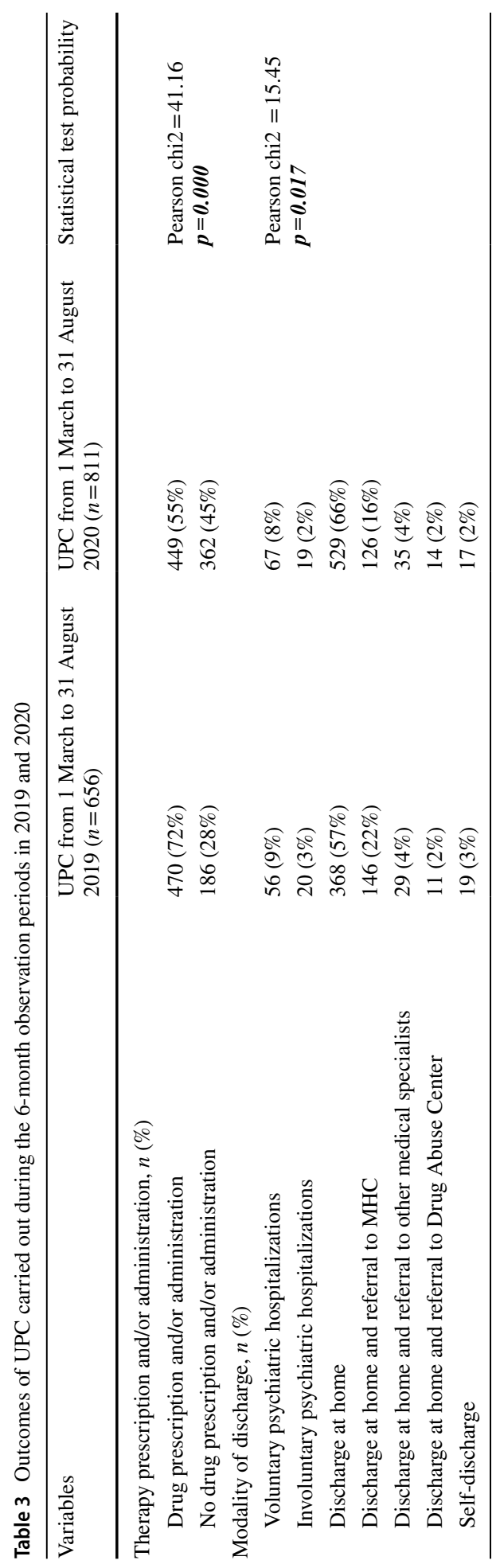




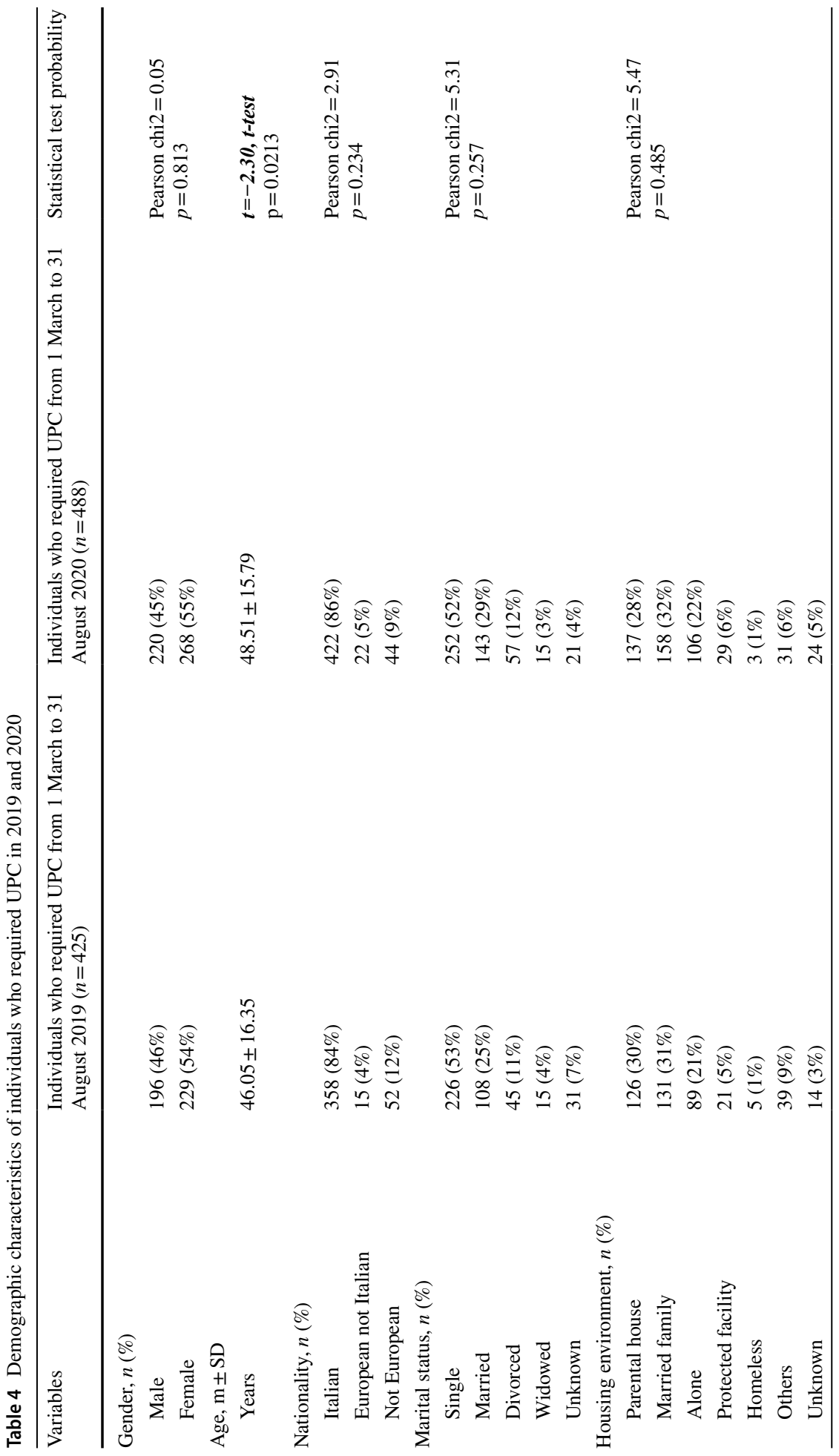




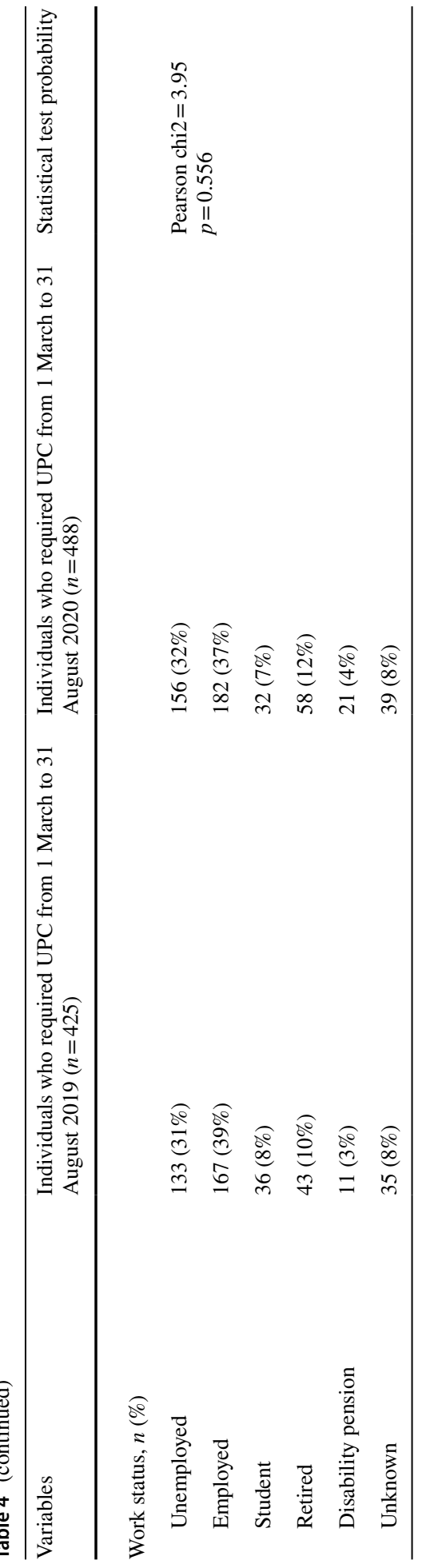




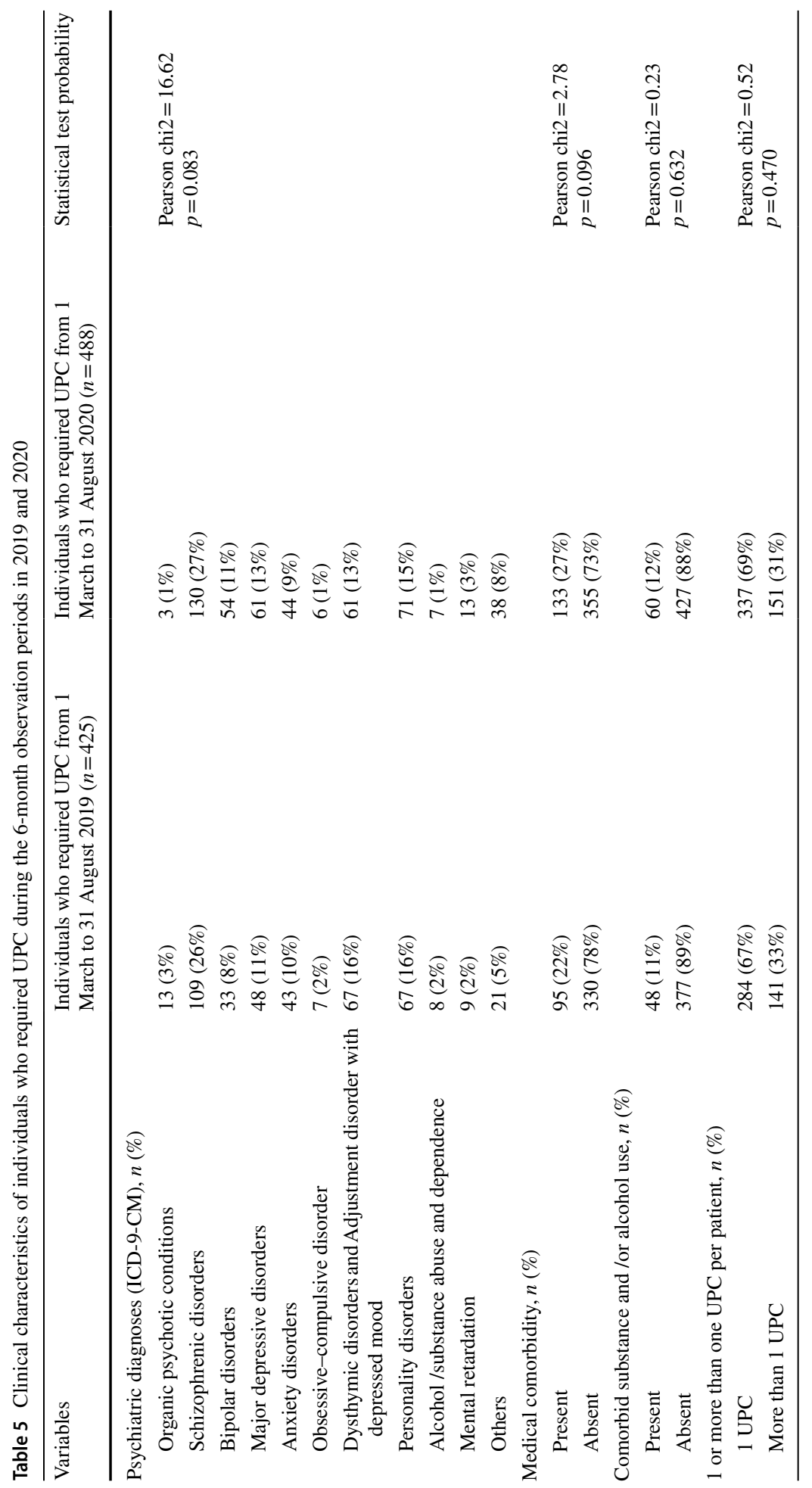




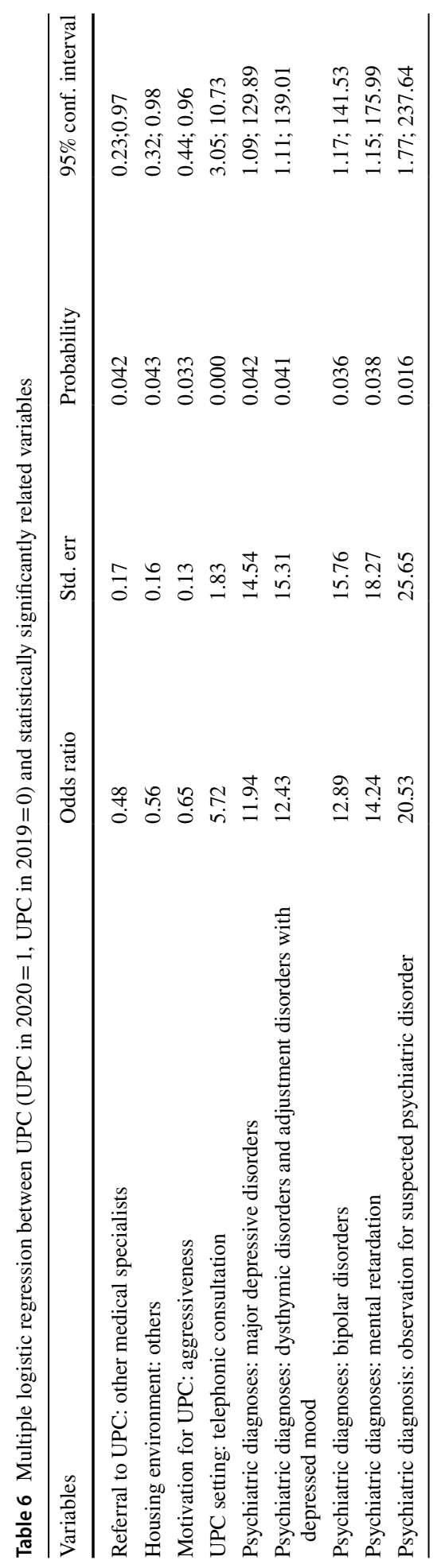




\section{Discussion}

Our study was aimed at evaluating the impact of the Coronavirus pandemic on an outpatient mental health services, in particular on emergency psychiatric consultants provided by outpatient MHC.

The SARS Cov-2 virus pandemic has had a devastating impact on the functioning of mental health services in most countries around the world, in accordance with the online WHO's Big Event For Mental Health on 10 October 2020 [4]. A recent survey, carried out in 130 countries, has highlighted in $93 \%$ of countries a greater demand for mental health visits leading to the need to increase investment in this field, given the current shortage. The WHO had previously highlighted the underfunding of mental health services, given that, prior to the pandemic, countries spent less than $2 \%$ of their GDP on mental health investments.

In particular, the recent WHO survey has highlighted two main criticalities: on the one hand, the increased request for psychiatric consultations due to a more widespread psychological sufferance related to conditions such as fear, isolation, reduced economic income, uncertainty for the future as well as psychiatric complications directly caused by COVID19; on the other hand, the difficulty in respecting the safety standards provided for the pandemic, which has led to a marked reduction in the services provided [4].

Over $60 \%$ of the countries evaluated have reported a reduction in mental health services for vulnerable people (children, adolescents, the elderly, as well as pregnant women), 67\% of the countries have reported the interruption in counselling services, $49 \%$ in psychotherapy, $45 \%$ in clinical activities for pathological addictions and 30\% have reported interruptions in visits for the treatment of mental, neurological and substance abuse related disorders [4]. About $70 \%$ of the countries surveyed have used tele-medicine and tele-therapy techniques to overcome the interruption of services provided in person. Disparities in the ability to deliver such interventions were noted, with a great disparity in the part of developing countries, which have not been able to offer these services.

In our study we highlighted a global increase of UPC (811 in 2020 vs 656 in 2019) in 2020 as well as of the average number of daily consultations (5.3 vs 4.07), which resulted in an increased workload for $\mathrm{MHC}$, which continued to provide urgent services despite the limitations imposed by pandemic containment measures. In our MHC, during the lockdown period, non-urgent outpatient visits were suspended, but psychiatrists and nurses continued to provide emergency services, even changing their daily clinical practices. Upon access to the MHC, in accordance with the national and local guidelines, the patient requesting a consultation underwent body temperature measurement and evaluation of breathing problems and other symptoms related to SARS-CoV-2 infection in the socalled filter zone, set up by the service to avoid the spread of COVID-19 infection. In case of infection suspected, the physician and nursing staff adopted individual protection measures, kept the patient in the filter area during the evaluation for urgent psychiatric consultation and sent him/her to perform a screening test for COVID-19. Otherwise, if infection was not suspected, the patient was welcomed by the nursing staff, who carried out an initial assessment for UPC. In case UPC was necessary, the patient had access to an interview with the medical staff and, if not, the patient could be cared by the nurse on duty and then sent home, with care continuity ensured by telephone.

The increased number of UPC at MHC we recorded is in contrast with the significant reduction of UPC recorded at Emergency Rooms in hospitals of many countries during the lockdown period, as highlighted by most studies [35-37]. This data could represent 
a possible explanation of the increased number of consultations at MHC we detected, because it could be interpreted as the patient's attempts to avoid the risk of COVID-19 contagion, as noted by another author [38]. This result is further confirmed by the significant increase in the number of UPC at MHC requested spontaneously or on the recommendation of the GP in 2020 while referral from other outpatient services, probably due to the activity reduction imposed by pandemic containment measures.

More patients who required an UPC at MHC were already in care at the outpatient service in 2020. This data could indicate the higher vulnerability of patients affected by a psychiatric disorder to the effects of the pandemic situation, as observed by most authors $[35,39,40]$.

In 2020, the modality of carrying out consultations also changed at MHC: in 2020 telephone consultations were 5 times higher than in 2019 (126 vs 25) in order to reduce the risk of infection transmission. In all parts of the world, the pandemic has partially disrupted the traditional practice of psychiatric assessment and treatment through face-to-face interaction and telemedicine has therefore become a tool that has helped to minimize interruptions in patient care [41, 42]. Also in the psychiatric field, telemedicine has assumed an important role in guaranteeing continuity of care during the pandemic: the psychiatrists and nurses of MHC have to assess the psychological state of patients and provide them the necessary support through telephone contact at the same time evaluating the necessity of urgent treatments.

This result highlights the importance of so called tele-psychiatry, which permitted professional contacts with patients by telephone, messages and video calls with patients even during social distancing periods. Another study has recently highlighted that telehealth has permitted health services to maintain the continuity of care during this COVID-19 pandemic despite the difficulties in delivering therapies and the potential limitations to confidentiality [43]. Telehealth service has been evaluated as particularly feasible and appropriate for patients and their families and /or caregivers during this COVID-19 pandemic [32]. The widespread use of tele-psychiatry in daily clinical practice leads to the need to update guidelines on good practices in order to integrate this method well in contemporary psychiatry.

In 2020, most UPC were required by patients already treated and cared for by the outpatient service in comparison with 2019 (86\% vs 79\%), suggesting the psychological vulnerability of this population in the pandemic period probably due to many critical issues (isolation, fear of infection, economic difficulties, etc.), as noted by other authors [35-40]. We did not report any statistically significant difference in the clinical motivations for UPC, although our logistic regression model highlights that the UPC in 2020 were strongly conditioned by many psychiatric disorders as depressive, adjustment and bipolar disorders as well as mental retardation and suspected psychiatric disorder, further suggesting the greater vulnerability of people affected by these disorders. Moreover, our regression model confirmed that telephone consultation was another variable closely related to the UPC performed in 2020 .

In 2020, the outcomes of UPC at MHC presented statistically significant differences in comparison with those of the previous year: drug prescription and /or administration were reduced whereas discharge at home was increased. Reduced drug prescription can be explained by the high number of teleconsultations which did not permit the delivery of therapy, as observed by other authors [43]. We believe that the most frequent outcome of UPC in 2020, home discharge, may have been conditioned by the need to manage psychiatric disorders, albeit urgent and acute, on an outpatient basis, avoiding hospitalization when possible due to the risk of COVID-19 contagion, as other studies highlighted [27, 
$37,44]$. In addition, the number of involuntary hospitalizations did not change in the pandemic period compared to the previous year, reflecting risk factors previously evaluated [45]. Both data indicate the difficulties to treat and hospitalize patients during the pandemic period, which has led to the reduction of many therapeutic and rehabilitative activities of MHC during the pandemic emergency, as other authors highlighted [44].

In 2020, the number of individuals who required UPC was consistently higher compared to the previous year (425 vs 488) but their demographic and clinic characteristics were similar with the exception of age. In fact, patients who required UPC in 2020 were older than those of 2019, suggesting that, as the years grow, vulnerability to the biological, psychological and environmental consequences of pandemic increases, as reported by another recent study, which has highlighted a significant decline in psychiatric emergency interventions needed by children and adolescents, but an increase need in adults [28].

During the pandemic period, MHC has been identified as the point of reference that provides support to psychological suffering widespread in the COVID-19 emergency especially by patients already treated in the outpatient service. Nevertheless, up to now, little research on urgent psychiatric consultations at outpatient services is available in literature.

\section{Limitations}

The present study has several limitations. The first is its retrospective observational design which does not permit us causal inferences. Related to the retrospective design, we note the lack of data, previously collected in the database of the service not for the purpose of our research. The monocentric design of the study has the limitation of not permitting us to compare our results with other service data. Furthermore, the 6-month observation period is too short to report the psychological effects of the pandemic emergency, which are likely to take a long time to develop [17].

The advantages of this study are the analysis in a sufficiently large sample of a representative population of a MHC and its clinical activities in the recent COVID-19 pandemic, reporting the changes imposed by this emergency.

\section{Conclusions}

In light of our findings, we conclude that over the 6-month period of the Covid-19 pandemic we recorded an increased demand for urgent psychiatric consultations especially from the most clinically vulnerable patients and, simultaneously, a major change in the treatment modality provided by the our psychiatric service, which, although strongly influenced by the limits imposed by the pandemic emergency, has reshaped its activities to ensure continuity of care and support for patients, as demonstrated by the greater number of urgent consultations carried out in 2020.

\section{Declarations}

Ethical Approval and Consent to Participate This study was approved by the Ethics Committee of the Vasta Emilia Nord Area (protocol AOU 0016106/20) and authorized by the AUSL-Modena (No. 1381, 22-6-20).

Conflict of interest All authors declare that they have no conflicts of interest. 


\section{References}

1. Kakodkar P, Kaka N, Baig MN. A Comprehensive literature review on the clinical presentation, and management of the pandemic coronavirus disease 2019 (COVID-19). Cureus. 2020. https://doi. org/10.7759/cureus. 7560 .

2. Nicol GE, Karp JF, Reiersen AM, Zorumski CF, Lenze EJ. "What were you before the war?" Repurposing psychiatry during the COVID-19 pandemic. J Clin Psychiatry. 2020. https://doi.org/ 10.4088/JCP.20com13373.

3. Brooks SK, Webster RK, Smith LE, Woodland L, Wessely S, Greenberg N, Rubin GJ. The psychological impact of quarantine and how to reduce it: rapid review of the evidence. Lancet. 2020. https://doi.org/10.1016/S0140-6736(20)30460-8.

4. World Health Organization. The impact of COVID-19 on mental, neurological and substance use services: results of a rapid assessment. 2020. https://www.who.int/publications/i/item/9789240124 55. Accessed 10 Nov 2020.

5. Parra A, Juanes A, Losada CP, Álvarez-Sesmero S, Santana VD, Martí I, Urricelqui J, Rentero D. Psychotic symptoms in COVID-19 patients. A retrospective descriptive study. Psychiatry Res. 2020. https://doi.org/10.1016/j.psychres.2020.113254.

6. Valdés-Florido MJ, López-Díaz Á, Palermo-Zeballos FJ, Martínez-Molina I, Martín-Gil VE, Crespo-Facorro B, Ruiz-Veguilla M. Reactive psychoses in the context of the COVID-19 pandemic: clinical perspectives from a case series. Rev Psiquiatr Salud Ment. 2020. https://doi.org/10.1016/j. rpsm.2020.04.009.

7. Garfin DR, Silver RC, Holman EA. The novel coronavirus (COVID-2019) outbreak: amplification of public health consequences by media exposure. Health Psychol. 2020. https://doi.org/10.1037/ hea0000875.

8. Heitzman J. Impact of COVID-19 pandemic on mental health. Psychiatr Pol. 2020. https://doi.org/ $10.12740 / \mathrm{PP} / 120373$.

9. Jeste DV, Lee EE, Cacioppo S. Battling the modern behavioral epidemic of loneliness: suggestions for research and interventions. JAMA Psychiatry. 2020. https://doi.org/10.1001/jamapsychiatry. 2020.0027.

10. Wang C, Pan R, Wan X, Tan Y, Xu L, Ho CS, Ho RC. Immediate psychological responses and associated factors during the initial stage of the 2019 coronavirus disease (COVID-19) Epidemic among the general population in China. Int J Environ Res Public Health. 2020. https://doi.org/10. 3390/ijerph17051729.

11. Shi L, Lu ZA, Que JY, Huang XL, Liu L, Ran MS, Gong YM, Yuan K, Yan W, Sun YK, Shi J, Bao YP, Lu L. Prevalence of and risk factors associated with mental health symptoms among the general population in China during the coronavirus disease 2019 pandemic. JAMA Netw Open. 2020. https://doi.org/10.1001/jamanetworkopen.2020.14053.

12. Torales J, O'Higgins M, Castaldelli-Maia JM, Ventriglio A. The outbreak of COVID-19 coronavirus and its impact on global mental health. Int J Soc Psychiatry. 2020. https://doi.org/10.1177/ 0020764020915212.

13. Li S, Wang Y, Xue J, Zhao N, Zhu T. The Impact of COVID-19 epidemic declaration on psychological consequences: a study on active Weibo users. Int J Environ Res Public Health. 2020. https:// doi.org/10.3390/ijerph17062032.

14. Salari N, Hosseinian-Far A, Jalali R, Vaisi-Raygani A, Rasoulpoor S, Mohammadi M, Rasoulpoor S, Khaledi-Paveh B. Prevalence of stress, anxiety, depression among the general population during the COVID-19 pandemic: a systematic review and meta-analysis. Glob Health. 2020. https://doi. org/10.1186/s12992-020-00589-w.

15. Calati R, Ferrari C, Brittner M, Oasi O, Olié E, Carvalho AF, Courtet P. Suicidal thoughts and behaviors and social isolation: a narrative review of the literature. J Affect Disord. 2019. https:// doi.org/10.1016/j.jad.2018.11.022.

16. Lima CKT, Carvalho PM, Lima I, Nunes JVA, Saraiva JS, de Souza RI, da Silva CGL, Neto LRN. The emotional impact of coronavirus 2019-nCoV (new Coronavirus disease). Psychiatry Res. 2020. https://doi.org/10.1016/j.psychres.2020.112915.

17. Taylor S. The psychology of pandemics: preparing for the next global outbreak of infectious disease. Newcastle upon Tyne: Cambridge Scholars Publishing; 2019.

18. Fiorillo A, Gorwood P. The consequences of the COVID-19 pandemic on mental health and implications for clinical practice. Eur Psychiatry. 2020. https://doi.org/10.1192/j.eurpsy.2020.35.

19. American Psychiatric Association. Diagnostic and statistical manual of mental disorders. 5th ed. Washington, DC: American Psychiatric Association; 2013. 
20. Wheat S, Dschida D, Talen MR. Psychiatric emergencies. Prim Care. 2016. https://doi.org/10.1016/j. pop.2016.01.009.

21. Zun LS. Pitfalls in the care of the psychiatric patient in the emergency department. J Emerg Med. 2012;43:829-35. https://doi.org/10.1016/j.jemermed.2012.01.064.

22. Giberti F, Rossi R. Manuale di psichiatria: per studenti, medici, psicologi, tecnici della riabilitazione, assistenti sociali, operatori psichiatrici. Padova: Piccin Editore; 2009.

23. Larkin GL, Claassen CA, Emond JA, Pelletier AJ, Camargo CA. Trends in U.S. emergency department visits for mental health conditions, 1992 to 2001. PsychiatrServ. 2005. https://doi.org/10.1176/appi.ps. 56.6.671.

24. Ministero della Salute. Che cos'è la salute mentale? [Ministry of Health. What is mental health?] http://www.salute.gov.it/portale/temi/p2_6.jsp?id=171\&area=salute\%20mentale\&menu=vuoto. 2013. Accessed 7 Oct 2020.

25. Ministero della Salute. Documento Conferenza Unificata. Definizione dei percorsi di cura da attivare nei dipartimenti di salute mentale per i disturbi schizofrenici, i disturbi dell'umore e i disturbi gravi di personalità. [Ministry of Health. Unified Conference Document. Definition of the treatment programs to be implemented in Mental Health Departments for schizophrenic disorders, mood disorders and severe personality disorders.] 2014. www.salute.gov.it/portale/documentazione/p6_2_2_1.jsp?id= 2461. Accessed 10 Sept 2020.

26. Servizio Sanitario Regionale Emilia-Romagna. Starace F. Il Dipartimento di Salute Mentale e Dipendenze Patologiche dell'Azienda Unità Sanitaria Locale di Modena. Struttura e attività di un sistema di cura integrato. [Emilia-Romagna Regional Health Service. Starace F. The Department of Mental Health and Pathological Addictions of the Local Health Unit of Modena. Structure and activities of an integrated care system.] 2019. http://www.ausl.mo.it/salutementale. Accessed 23 Sept 2020.

27. D'Agostino A, Demartini B, Cavallotti S, Gambini O. Mental health services in Italy during the COVID-19 outbreak. Lancet Psychiatry. 2020. https://doi.org/10.1016/S2215-0366(20)30133-4.

28. Ferrando SJ, Klepacz L, Lynch S, Shahar S, Dornbush R, Smiley A, Miller I, Tavakkoli M, Regan J, Bartell A. Psychiatric emergencies during the height of the COVID-19 pandemic in the suburban New York City area. J Psychiatr Res. 2020. https://doi.org/10.1016/j.jpsychires.2020.10.029.

29. Li W, Yang Y, Liu ZH, Zhao YJ, Zhang Q, Zhang L, Cheung T, Xiang YT. Progression of Mental Health Services during the COVID-19 Outbreak in China. Int J Biol Sci. 2020. https://doi.org/10.7150/ijbs. 45120.

30. Percudani M, Corradin M, Moreno M, Indelicato A, Vita A. Mental health services in Lombardy during COVID-19 outbreak. Psychiatry Res. 2020. https://doi.org/10.1016/j.psychres.2020.112980.

31. Società Italiana di Epidemiologia Psichiatrica. Istruzioni operative per le attività di dipartimenti di salute mentale in corso di emergenza coronavirus. [Italian Society of Psychiatric Epidemiology. Operational instructions for the activities of mental health departments during coronavirus emergency.] 2020. https://siep.it/istruzioni-operative-siep/. Accessed 23 Sept 2020.

32. Di Carlo F, Sociali A, Picutti E, Pettorruso M, Vellante F, Verrastro V, Martinotti G, di Giannantonio M. Telepsychiatry and other cutting-edge technologies in COVID-19 pandemic: bridging the distance in mental health assistance. Int J Clin Pract. 2021. https://doi.org/10.1111/ijcp.13716.

33. Moreno C, Wykes T, Galderisi S, Nordentoft M, Crossley N, Jones N, Cannon M, Correll CU, Byrne L, Carr S, Chen EYH, Gorwood P, Johnson S, Kärkkäinen H, Krystal JH, Lee J, Lieberman J, LópezJaramillo C, Männikkö M, Phillips MR, Uchida H, Vieta E, Vita A, Arango C. How mental health care should change as a consequence of the COVID-19 pandemic. Lancet Psychiatry. 2020. https://doi.org/ $10.1016 / \mathrm{S} 2215-0366(20) 30307-2$.

34. Ministry of Labour, Health and Social Policy. International classification of diseases-9th revision-clinical modification. Roma: IstitutoPoligrafico e ZeccadelloStato; 2008.

35. Capuzzi E, Di Brita C, Caldiroli A, Colmegna F, Nava R, Buoli M, Clerici M. Psychiatric emergency care during Coronavirus 2019 (COVID 19) pandemic lockdown: results from a Department of Mental Health and Addiction of northern Italy. Psychiatry Res. 2020. https://doi.org/10.1016/j.psychres.2020.113463.

36. Gonçalves-Pinho M, Mota P, Ribeiro J, Macedo S, Freitas A. The impact of COVID-19 pandemic on psychiatric emergency department visits - a descriptive study. Psychiatr Q. 2020. https://doi.org/10. 1007/s11126-020-09837-z.

37. Dragovic M, Pascu V, Hall T, Ingram J, Waters F. Emergency department mental health presentations before and during the COVID-19 outbreak in Western Australia. Australas Psychiatry. 2020. https:// doi.org/10.1177/1039856220960673.

38. Forte G, Favieri F, Tambelli R, Casagrande M. The enemy which sealed the world: effects of covid19 diffusion on the psychological state of the Italian population. J Clin Med. 2020. https://doi.org/10. $3390 / \mathrm{jcm} 9061802$.

39. Chevance A, Gourion D, Hoertel N, Llorca PM, Thomas P, Bocher R, Moro MR, Laprévote V, Benyamina A, Fossati P, Masson M, Leaune E, Leboyer M, Gaillard R. Ensuring mental health care during 
the SARS-CoV-2 epidemic in France: a narrative review. Encephale. 2020. https://doi.org/10.1016/j. encep.2020.04.005.

40. Kar SK, Singh A. Mental health of mental health professionals during COVID-19 pandemic: who cares for it? Asian J Psychiatr. 2020. https://doi.org/10.1016/j.ajp.2020.102385.

41. Chen JA, Chung WJ, Young SK, Tuttle MC, Collins MB, Darghouth SL, Longley R, Levy R, Razafsha M, Kerner JC, Wozniak J, Huffman JC. COVID-19 and telepsychiatry: early outpatient experiences and implications for the future. Gen Hosp Psychiatry. 2020. https://doi.org/10.1016/j.genhosppsych.2020.07.002.

42. O'Brien M, McNicholas F. The use of telepsychiatry during COVID-19 and beyond. Ir J Psychol Med. 2020. https://doi.org/10.1017/ipm.2020.54.

43. Sklar M, Reeder K, Carandang K, Ehrhart MG, Aarons GA. An Observational Study of the Impact of COVID-19 and the Transition to Telehealth on Community Mental Health Center Providers. Preprint. Res Sq. 2020. https://doi.org/10.21203/rs.3.rs-48767/v1.

44. Carpiniello B, Tusconi M, di Sciascio G, Zanalda E, di Giannantonio M, Executive Committee of the Italian Society of Psychiatry. Mental health services in Italy during the COVID-19 pandemic. Psychiatry ClinNeurosci. 2020. https://doi.org/10.1111/pcn.13082.

45. Di Lorenzo R, Vecchi L, Artoni C, Mongelli F, Ferri P. Demographic and clinical characteristics of patients involuntarily hospitalized in an Italian psychiatric ward: a 1-year retrospective analysis. Acta Biomed. 2018. https://doi.org/10.23750/abm.v89i6-S.7392.

Publisher's Note Springer Nature remains neutral with regard to jurisdictional claims in published maps and institutional affiliations.

Rosaria Di Lorenzo, MD Psychiatrist in the Department of Mental Health and Drug Abuse of AUSL-Modena from 18/6/91 up to now; adjunct professor in School of Specialization in Psychiatry, University Course of Psychiatric Rehabilitation Technicians and Nursing Programme of University of Modena and Reggio Emilia; National Scientific Habilitation as associate professor of Psychiatry on 24/07/2018.

Gianluca Fiore, MD Medical degree awarded on October 2017 at the University of Bari with the thesis "Denial of pregnancy: a literature's review". Degree mark: 110/110 cum laude. Resident in School of Specialization in Psychiatry, University of Modena and Reggio Emilia.

Alessandra Bruno, RN Nursing degree at the University of Modena and Reggio Emilia (16th December 2020) with degree mark of $110 / 110$.

Margherita Pinelli, MD Resident in School of Specialization in Psychiatry, University of Modena and Reggio Emilia.

Davide Bertani, MD with degree mark of 110/110 cum laude. Resident in School of Specialization in Psychiatry, University of Modena and Reggio Emilia.

Patrizia Falcone, RN Nursing Degree on July 1996 at the University of Modena and Reggio Emilia. Nurse in the Psychiatric Intensive Treatment Facility of the Department Mental Health and Drug Abuse of AUSLModena from 02/05/2000 up to now.

Donatella Marrama, MD Psychiatrist: Director of the Complex Operational Unit "Adult Mental Health Center" of the Department of Mental Health and Drug Abuse of AUSL-Modena (from 16-10-2020 to date).

Fabrizio Starace, MD Psychiatrist, Director of the Department of Mental Health and Pathological Addictions of the AUSL of Modena, President of the Italian Society of Psychiatric Epidemiology (SIEP), adjunct professor in School of Specialization in Psychiatry, University of Modena and Reggio Emilia, member of the Italian Superior Health Council and member of the Committee of experts in economic and social matters set up by the Italian Presidency of the Council of Ministers.

Paola Ferri, RN coordinator of the Nursing Degree Program (2003-2016), University of Modena and Reggio Emilia; dean of the Nursing Degree Program (from 01/01/2016 at present), Associate Professor of Nursing (from 01/11/2017 at present), University of Modena and Reggio Emilia, Italy. 


\section{Authors and Affiliations}

\section{Rosaria Di Lorenzo ${ }^{1}$. $\cdot$ Gianluca Fiore ${ }^{2} \cdot$ Alessandra Bruno $^{3} \cdot$ Margherita Pinelli $^{2}$.} Davide Bertani $^{2} \cdot$ Patrizia Falcone ${ }^{1} \cdot$ Donatella Marrama $^{4} \cdot$ Fabrizio Starace $^{5}$. Paola Ferri' ${ }^{6}$

Gianluca Fiore

gianluca.fiore1991@gmail.com

Alessandra Bruno

alessandra.bruno1276@gmail.com

Margherita Pinelli

margheritapinelli90@gmail.com

Davide Bertani

dbertani92@gmail.com

Patrizia Falcone

p.falcone@ausl.mo.it

Donatella Marrama

d.marrama@ausl.mo.it

Fabrizio Starace

f.starace@ausl.mo.it

Paola Ferri

paola.ferri@unimore.it

1 Psychiatric Intensive Treatment Facility, Mental Health and Drug Abuse Department of AUSLModena, Via Paul Harris, 175, 41122 Modena, Italy

2 University of Modena and Reggio Emilia, Via del Pozzo, 71, 41124 Modena, Italy

3 School of Nursing, University of Modena and Reggio Emilia, Via del Pozzo, 71, 41124 Modena, Italy

4 Mental Health and Drug Abuse Department of AUSL-Modena, Via Paul Harris, 175, 41122 Modena, Italy

5 Mental Health and Drug Abuse Department of AUSL-Modena, Italian Society of Epidemiological Psychiatry (SIEP), Viale L.A. Muratori 201, 41124 Modena, Italy

6 Department of Biomedical, Metabolic and Neural Sciences, Via G. Campi, 287, 41125 Modena, Italy 